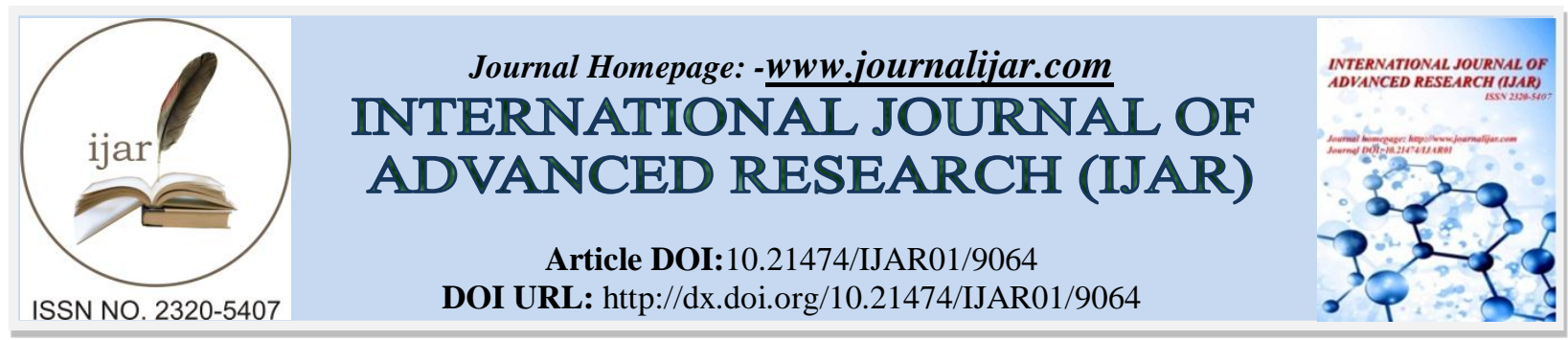

RESEARCH ARTICLE

\title{
THE MEDIATING EFFECT OF EMPLOYEE RELATIONS ON THE RELATIONSHIP BETWEEN EMOTIONAL INTELLIGENCE AND EMPLOYEES PERFORMANCE.
}

\author{
Mr. Jamshed Khaliq ${ }^{1}$ And Dr. Aftab Alam ${ }^{2}$.
}

1. MS Scholar - Abasyn University Peshawar, KPK, Pakistan.

2. Assistant Professor - Abasyn University Peshawar, KPK Pakistan.

\section{Manuscript Info}

Manuscript History

Received: 14 March 2019

Final Accepted: 16 April 2019

Published: May 2019

Key words:-

Emotional intelligence, employee performance, employee relations.

\section{Abstract}

The study is conducted with aim to determine mediating effect of employee relations in association between emotional intelligence and employee performance. A random sample by adopting arbitrary approach, comprising of 165 employees of various levels from different manufacturing units in Peshawar, KPK, Pakistan was used to collect data by using adopted questionnaire. The findings have shown all mediation conditions verified and finally it is concluded that relationship between emotional intelligence and employee performance is mediated by employee relationship. Therefore, the antecedent of employee relations must be taken into account to enhance productivity and performance of employees.

Copy Right, IJAR, 2019,. All rights reserved.

\section{Introduction:-}

Organizations, in today's modern world has accepted the fact their employees, particularly those at the managerial level are of key importance for the maintenance of good working relation among the employees, in order to attain a good working environment and breed productive individuals.

A lead role is being played by Emotional intelligence in every organization that portrays proficiency, capacity, aptitude, talent, potential, dexterity and manages the sentiments \& sensation of one's self and others as well.

The Strengthen EI foreshadows more propitious consequences and enervated level of EI anticipates enhanced relationship antipathies (Mayer J., Salovey \& Caruso D., 2008). The managers with high ranked EI are more adept to originate effective and eternal relations with the employees and groups (Roste, D. and Ciarrocchi, J. 2005). To attain a communal intent of organization, a manager ought to know in what way to comprehend the feelings and emotions of others and construct a sound and intimated relations with them and among them. Realizing the sensations extends you to the intentions and motives of the people, whereas handling the emotions enable a person to deal with their feelings productively at work(King, Michelle and Gardner, Dianne 2006).As manager convey his exhilaration and zeal for commencement towards a particular task, the employees show their involvement and reactions in the same manner (Kausr, Jasvinder 2010). Emotional Intelligence is a momentous element that has great role in employee's and organization outcome (Lawler, E. E. 1996) and on this base it can be said that emotionally intelligent managers has vital influence on the productivity of the employee (Probst and Tahira, M. 2000) as the employee can only be made productive if his emotions are given value and they enjoys good relation at work. Researches reveals that managers with high level of emotional intelligence have relished more career success (Dulewics \& Higgs 2000), observes lesser job instability (Ashaknsay, Hartel\& Zerbe 2000), proved themselves more 
influential (Cooper \&Sawaf, 2001; Donaldson \&Stough 2002) and more adjustable in complicated circumstances (Slaski \& Cartwright) 2002), than those with low emotional intelligence.

The role of emotional intelligence on part of senior management in maintaining a good working environment and dominant good relationship among the employees and management in order to enhance their performance so as the organization goal can be accomplished cannot be ignored.

Goleman (1995)in his Book, "Emotional Intelligence", introduced notable associations of emotional intelligence also fairly enlarged the fabrication to incorporate a lot of specific social and communication skills persuaded by the awareness and mien of emotions. Cooper \&Sawaf (1997)in his book "Executive EQ", described emotional intelligence model that affiliates particular skills and tendencies to below mentioned four fundamentals: emotional literacy, it consist knowledge of one's own emotions and how they operates; emotional fitness, it contains emotional durability and resilience; emotional depth, it indicates emotional fervor and ability for development and "emotional alchemy", it includes the knack to use emotion in order light up creativity. In contemporary corporate world, the use of EI to improve relation of employees to management in order to improve their productivity is certainly a prime concern. This study intends to furnish bridge between emotional intelligence, employee-management relations and its influence on performance of the employees.

\section{Objectives the study}

The study is guided by the following objectives;

1. To examine the effect of Emotional Intelligence on employeesperformance.

2. To ascertain the effect of Emotional Intelligence on employees relations.

3. To verify the mediating role of employee relation in emotional intelligence and employee performance.

\section{Literature Review}

Research on EI is concentrated on framing EI as unique and independent intelligence, its linkages with employee's performance, impact on effective leadership particularly transformational and transactional leadership behavior. Satisfying the criteria for intelligence, EI has been certainly emerged as an independent intelligence. However, the influence of EI on performance is usually opposing with those researches concluding a strongly significant relationship to the other finding a weak relationship between EI and job performance and same trend is reflected for EI's effect on management effectiveness.

Emotional intelligence has emerged as challenging subject in scientific circles and in the lay public as well. The conceit itself links back to initial concerns in 1920s (for a counter check, see Baron and Parker, 2000). Several scholars in beginning of 1980s, started methodically gestate concept of emotional intelligence while other EQ concept developed by Gardner's (1983) conceptualizing interpersonal intelligence and Steiner (1984) studied on emotional refinement were fundamentals of what Salovey \& Mayer (1989-1990) first coined as emotional intelligence. Considering Baron's previous work as base, he considers emotional intelligence as irrational which is perceived as an attire of emotional, personal, social abilities and skills that effects individual's aptitude to cope productively with environmental demands and constraints.

The literature divulges assorted efforts to unify the emotional and social constituents like Howard Gardner (1983) revels his framework of personal intelligences to be based on intrapersonal (emotional) and interpersonal (social) intelligence. Carolyn Saarni (1990) reported emotional competence as containing eight interlinked emotional and social skills. Further, emotional-social intelligence is composed of many intrapersonal and interpersonal abilities, capabilities as catalyst, coupled to ascertain effective human behavior $(1988,1997 \mathrm{~b}, 2000)$.

Salovey \& Mayer (1990) documented a fabric for EI and outlined the antecedents of EI to social intelligence and brought it to lime light that how notion of emotion had been used in traditional intelligences. Further they elaborated by concluding EI is linked with good mental well and emotionally intelligent people are a pleasant association whereas those who are deficient in EI are normally unable to react successfully and satisfactorily to the demand of their environment. Mayer and Salovey (1997) debated emotional intelligence skills make an individual able to discern, realize and control emotions of himself and others, additionally itplay vital role in the creation or maintaining enhanced relationships in the workplace 
Cavallo (2001) undertaken a well-known investigation at Johnson \& Johnson consumer and personal care group entails 358 managers and 1abour 1400 employees in offices across the globe with aim of discovering the competencies that on the bases of which the performers can be ranked as high, average or low. He deducted from the same study that managers having high 'emotional competence' are best operating manager in comparison to those with low EI.

Rode et al. (2007) investigated direct and moderating effect of EI on employee's productivity among business students. The research deducted that managing psychological effects and personality traits, EI was found to ascertain a single gauge of inter local efficacy i.e. public speaking efficiencies. The study confirmed that EI has indirect relation on performance and obvious occupancy of EI skills does not assure effective performance, there must be an impetus to exercise it.

Mishra \& Mohapatra (2010) studied the linkage between EI and job performance of 90 high ranked employees employed in various organizations at Delhi. The conclusion is a significant positive relationship between EI and job performance. The study also affirms the synchronizes validity of EI scale (EI test by Chadha and Singh, 2001). Additionally, only work experience was found to be positively correlated with EI out of various demographic variables.

Managers having greater emotional intelligence are likely to control stress and manage issues that may yield in relinquishment. Jordan et al. (2002) poor working relations may increase turnover in organizations and emotional intelligence may reduce turnover as employees are have the capacity to handle their emotions that arise from perceptions of job insecurity.

\section{Research Framework}

Following research framework has been designed for testing the above-mentioned hypothesis.

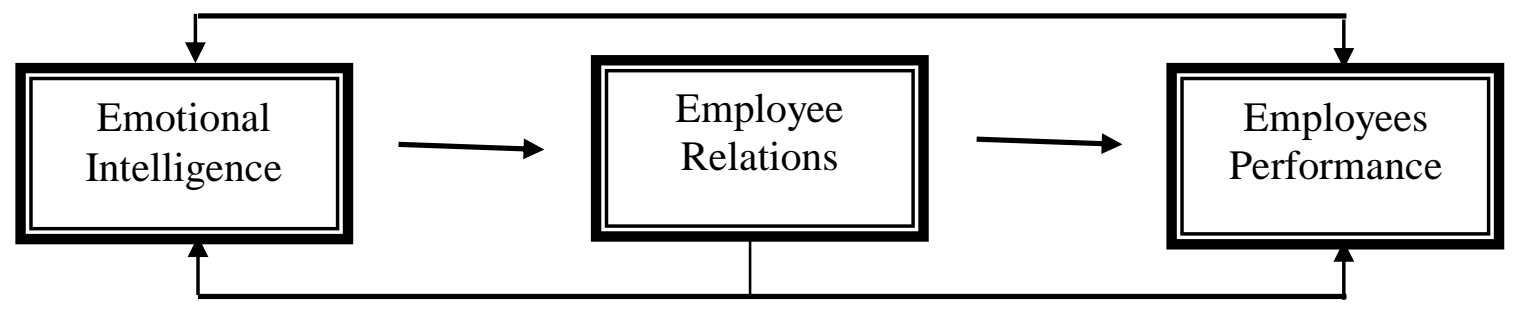

This research concentrates the effect of emotional intelligence over employees performance and the mediating role of employees relations. On the basis of literature review and research framework, following hypothesis have been developed.

1. $\mathrm{H}_{\mathrm{o}}$ : Emotional Intelligence has insignificant effect on employee performance

2. $\mathrm{H}_{1}$ : Emotional intelligence has significant effect on employee performance.

3. $\mathrm{H}_{\mathrm{o}}$ : Emotional intelligence has insignificant effect on employee relations.

4. $\mathrm{H}_{2}$ : Emotional intelligence has significant effect on employee relations.

5. $\mathrm{H}_{\mathrm{o}}$ : Employee relations has insignificant effect on employee performance.

6. $\mathrm{H}_{3}$ : Employee relations has significant effect on employee performance.

7. $\mathrm{H}_{\mathrm{o}}$ : Employee relations insignificantly mediates in a relationship with employee performance.

8. $\mathrm{H}_{4}$ : Employee relations significantly mediates in a relationship with employee performance.

\section{Methodology: - \\ Instruments}

To measure Emotional Intelligences a 29-item composite emotional intelligence scale made by(Hyde et al., 2001) was used. It is a 5-point (Likert, 1961) scale ranging from 1 (stronglydisagree) to 5 (strongly agree).

The 12-item scale was used to measure Employee relations. It was a 5-point (Likert, 1961) scale ranging from 1 (Strongly Agree) to 5 (Strongly Disagree) adopted from the study of (Biggs et al., 2016).

Employee performance is measured by using a 9-item scale developed by Goodman and Svyantek (1999) to undertake the study. It is a 5-point (Likert, 1961) scale ranging from 1 (Strongly Agree) to 5 (Strongly Disagree). 


\section{Sample Description}

Chahar\& Rana, (2014) carried out study on the EI by cosidering 155 respondents as a sample. Kannaiah, (2007) conducted study on EI by taking 150 respondents as a study sample. Therefore, arbitrary approach was used and 165 sample was chosen from manufacturing sector of Peshawar, KPK, Pakistan, keeping constraint of budget and time,

\section{Results and Discussions: - \\ Demographic Variables}

Results of demographic variables under consideration are listed in below table

Table I:-Gender

\begin{tabular}{|l|l|l|}
\hline Gender & Frequency & Percent \\
\hline Male & 102.0 & 62.0 \\
\hline Female & 63.0 & 38.0 \\
\hline Total & 165.0 & 100.0 \\
\hline
\end{tabular}

Number and percentage of female and male participants included in study have been shown in table mentioned above. It was found total 102 out of 165 male respondents i.e. about $62 \%$ of the sample size, wherease 63 out of 165 female respondents were found to be $38 \%$ of the total sample size.

Table II :-Age

\begin{tabular}{|l|l|l|}
\hline Age & Frequency & Percent \\
\hline $18-28$ & 129 & 78.0 \\
\hline $29-39$ & 26 & 16.0 \\
\hline 40 and above & 10 & 6.0 \\
\hline Total & 165 & 100.0 \\
\hline
\end{tabular}

The ages of the respondents are shown in above displayed table. 129 out of 165 Respondents were found to be the age ranging from 18-28 years are, which are 78\% of the sample size. 29-39 and 40 ages of the respondents were found to be 26 and 8 that are $16 \%$ and $6 \%$ of the sample size respectively.

\section{Reliability Analysis}

Cronbach's Alpha was used in order to check reliability of the data, . The greater / enhanced value of alpha nearer to 1 portrays higher internal consistency of items.

Table 3:-Reliability Statistics

\begin{tabular}{|l|l|l|}
\hline Variables & Cronbach's $\boldsymbol{\alpha}$ & No of Items \\
\hline Emotional Intelligence & .759 & 29 \\
\hline Employees Performance & .726 & 9 \\
\hline Employees Relations & .801 & 12 \\
\hline
\end{tabular}

Results of Cronbach's alpha for different variables is shown in above displayed table. variables have to be declared un-reliable, in case its alpha value is found to less than 0.70 (Sekaran, 2007). Therefore, the variables mentioned in above table are reliable becasue they were in possession of alpha values greater than 0.70 . Therefore, they could be used for further analysis being reliable.

\subsection{Regression Analysis}

Regression issaid to bea statistical technique, being adopted for finding effect of various dependent and independent variables on each other. It indulges tools to analyze / model various dependent and independent variables. More precisely, it assists in knowing, if one-unit change exists in the independent variable, how many units change is caused in the dependent variable. Furthermore, analysis of the data collected for this study is carried out through hierarchical regression developed by Barons and Kenny (1986).

Table 4:-The effect of Emotional intelligence on Employees Performance.

\begin{tabular}{|l|l|l|l|l|}
\hline Model & Unstandardized Coefficients & $\begin{array}{l}\text { Standardized } \\
\text { Coefficients }\end{array}$ & S & Sig. \\
\hline
\end{tabular}




\begin{tabular}{|l|l|l|l|l|l|l|}
\hline \multicolumn{2}{|l|}{} & B & Std. Error & Beta & & \\
\hline \multirow{2}{*}{1} & (Constant) & 8.448 & .381 & & 22.184 & .000 \\
\cline { 2 - 6 } & EI & .256 & .029 & .465 & 8.675 & .000 \\
\hline \multicolumn{2}{|l|}{ R Square $=.216$, F-value $=75.255$ With p value $=0.000$} \\
\hline
\end{tabular}

Effect of Emotional intelligence on Employees performance was measured as shown in above table. As per ANOVA results p-value of F-statistics is found to be lower than .05 and indicates significant along with fitness of regression model. It is notified that to asses extent of degree of change in dependent variable is elaborated by the independent variable is detected through $\mathrm{R}$-square. In above mentioned result, value of $\mathrm{R}$-square has been found to be .216 or $21.6 \%$, which indicates about $21.6 \%$ of the change in Employee performance is elaborated by emotional intelligence. The coefficient of regression in respect of independent variable is noted to be positive i.e .465 , therefore portrays positive relationship between the EI and EP. Hence, conclusion is, change of one unit in EI will enhance EP by .256 units. Therefore, alternate hypothesis has been accepted i.e. EI significantly positively effect on employee'sperformance.

Fig 1:-The effect of Emotional Intelligence on Employee Relations.

\begin{tabular}{|l|l|l|l|l|l|l|}
\hline \multicolumn{2}{|l|}{ Model } & \multicolumn{2}{|l|}{ Unstandardized Coefficients } & $\begin{array}{l}\text { Standardized } \\
\text { Coefficients }\end{array}$ & \multirow{2}{*}{ Sig. } \\
\cline { 3 - 6 } \multicolumn{2}{l|}{} & B & Std. Error & Beta & \\
\hline \multirow{2}{*}{1} & (Constant) & 10.975 & .670 & & 16.386 & .000 \\
\cline { 2 - 6 } & EI & .371 & .052 & .397 & 7.145 & .000 \\
\hline
\end{tabular}

$\mathrm{R}$ Square $=3.97, \mathrm{~F}-$ value $=51.053 \mathrm{With} \mathrm{p}$ value $=0.000$

The effect of Emotional intelligence on employee relations was calculated as shown in above table. It is noticed that the p-value of F-statistics lesser than .05 as per results of ANOVA and it indicates significance of the entire model. Value of R-square is found to be 397 in the above results, which concludes that $39.7 \%$ of the variance in employee relation is explained by emotional intelligence. EI's regression coefficient of is found to be .397, which displays $40 \%$ positive effect of EI on ER. Therefore, change of one unit in EI will result in increasing employee relation by .371 units. On this base alternative hypothesis is accepted i.e. EI has significant positive effect employee relations.

Table 5:-The effect of Employee Relations on Employee Performance.

\begin{tabular}{|l|l|l|l|l|l|l|}
\hline \multicolumn{2}{|l|}{ Model } & \multicolumn{2}{l|}{ Unstandardized Coefficients } & $\begin{array}{l}\text { Standardized } \\
\text { Coefficients }\end{array}$ & \multirow{2}{*}{ Sig. } \\
\cline { 3 - 5 } \multicolumn{2}{l|}{} & B & Std. Error & Beta & \\
\hline \multirow{2}{*}{1} & (Constant) & 8.631 & .540 & & 15.974 & .000 \\
\cline { 2 - 6 } & ER & .189 & .034 & .321 & 5.609 & .000 \\
\hline
\end{tabular}

$\mathrm{R}$ Square $=.321, \mathrm{~F}-$ value $=31.457, \mathrm{p}$ value $=0.000$

Effect of employee relations on employee performance was measured as shown in above table. As per ANOVA results p-value of F-test is lesser than .05 and it shows overall regression model to significant. As per above result, value of $\mathrm{R}$-square is found to be .321 which shows that $32.1 \%$ of the variance in employee performance is explained by employee relations. The regression coefficient is found to be .321of employee relations, which displays $32.1 \%$ positive effect of employee relations on employees performance. Therefore, it is concluded that change of one unit in employee relations will enhance employeesperformance by .189 units. On basis of these figres alternative hypothesis is accepted i.e. employee relation has significant positive effect upon employee performance.

Table IV:-Coefficients

\begin{tabular}{|c|c|c|c|c|c|c|}
\hline \multirow{2}{*}{\multicolumn{2}{|c|}{ Model }} & \multicolumn{2}{|c|}{ Unstandardized Coefficients } & \multirow{3}{*}{$\begin{array}{l}\text { StandardizedCoefficients } \\
\text { Beta }\end{array}$} & \multirow{3}{*}{$\begin{array}{l}\mathrm{t} \\
22.184\end{array}$} & \multirow{3}{*}{$\begin{array}{l}\text { Sig. } \\
.000\end{array}$} \\
\hline & & \multirow{2}{*}{$\begin{array}{l}\text { B } \\
8.448\end{array}$} & \multirow{2}{*}{$\begin{array}{l}\text { Std. Error } \\
.381\end{array}$} & & & \\
\hline 1 & (Constant) & & & & & \\
\hline & EI & .256 & .029 & .465 & 8.675 & .000 \\
\hline \multirow[t]{3}{*}{2} & (Constant) & 7.397 & .530 & & 13.966 & .000 \\
\hline & EI & .220 & .032 & .400 & 6.944 & .000 \\
\hline & ER & .096 & .034 & .163 & 2.819 & .005 \\
\hline
\end{tabular}


The table above visualize result of the analysis between independent variable (Emotional Intelligence) and dependent variable (Employee Performance) whereas Employees relation is taken as a mediator. EI'sbeta values varies from (8.65 to 6.94) and indicates significance in both steps. As per researches carried out by (Barons and Kenny, 1986; Fatima, et al; 2010), in case of relation between independent and dependent variables is originated to be significant in both first, second steps, therefore, can be concluded on this base that mediator variable to a limited extent or significantly mediates the association with independent and dependent variables, Furthermore in case the relationship founds to be insignificant it points out full or insignificant mediation in the said relation. The figures of emotional intelligence in both above shown steps are significant at $\mathrm{P}<.000$ which is lower than .05 , therefore acceptance of alternate hypotheses is dominant. Hence, employee relations mediate the relationship with EI and EP.

\section{Conclusion:-}

This research work examined how emotional intelligence might effect employee performance while employee relations mediates the relationship of above mentioned two variables. The results advocate a mediating effect of employee relations - between relationship of emotional intelligence and employee performance. Furthermore, it may also be concluded that significance of relationship beween EI and EP depends on the extent of employee relations.

\section{Limitations and future research}

One of the basic limitations of this study is cross-sectional design employed. According to Albdour \& Altarawneh (2014) changes in variables cannot be reflected through this research design whereas size of the sample selected is another limitation as it can affects generalizability of the study findings. Further research may be carried by employing same variable in other area or by enhancing sample size to get more generalize results.

\section{References:-}

1. Adhia, H., Nagendra, H. R., \& Mahadevan, B. (2010). Impact of adoption of yoga way of lifeon the emotional intelligence of managers. IIMB Management Review, 22(1-2), 32-41.doi: 10.1016/j.iimb.2010.03.003

2. Ashkanasy, N. M., Härtel, C. E. J., \& Zerbe, W. J. (2000). Emotions in the workplace: Research, theory, and practice. In N. M. Ashkanasy, C. E. Härtel\& W. J. Zerbe (Eds.),Emotions in the workplace: Research, theory, and practice (pp. 3-18). Westport, CT,US: Quorum Books/Greenwood Publishing Group.

3. Bar-On, R. (1997). The emotional intelligence inventory (EQ-I): Technical manual. Toronto,Canada: MultiHealth Systems.

4. Bar-On, R. (2000). Emotional and social intelligence: insights from the Emotional QuotientInventory The handbook of emotional intelligence (I ed., pp. 363-388): Jossey-Bass,San Francisco.

5. Bar-On, R., Handley, R., \& Fund, S. (2006). The impact of emotional intelligence onperformance. Linking emotional intelligence and performance at work: Currentresearch evidence with individuals and groups, 3-19.

6. Boyatzis, R. E. (1982). The competent manager: A model for effective performance: WileyNew York.

7. Cherniss, C., \& Adler, M. (2000). Promoting emotional intelligence in organizations: Maketraining in emotional intelligence effective: American Society for Training andDevelopment.

8. Cooper, R., \&Sawaf, A. (2001). Executive EQ: Emotional Intelligence in Business: TexerePublishing.

9. Dulewicz, V., \& Higgs, M. (2000). Emotional intelligence - A review and evaluation study.Journal of Managerial Psychology, 15(4), 341-372. doi: 10.1108/02683940010330993

10. George, J. M. (2000). Emotions and leadership: The role of emotional intelligence. Human relations, 53(8), 1027-1055.

11. Goleman, D. (1996). Emotional Intelligence: Why It Can Matter More Than IQ: BloomsburyPublishing.

12. Gupta, S. (1996). Managerial Effectiveness: Conceptual Framework and Scale Development. Indian Journal of Industrial Relations, 31(3), 392-409. doi: 10.2307/27767425

13. Hyde, A., Pethe, S., \& Dhar, U. (2001). Emotional intelligence scale. Vedant publication,Lucknow.

14. Johnson, P. R., \&Indvik, J. (1999). Organizational benefits of having emotionally intelligent managers and employees. Journal of workplace learning, 11(3), 84-88.

15. Khokhar, C., \& Kush, T. (2009). Emotional Intelligence and Work Performance among Executives. Europe's Journal of Psychology, 5(1). doi: 10.5964/ejop.v5i1.280

16. Likert, R. (1961). New patterns of management: McGraw-Hill.

17. Mayer, J. D., \& Cobb, C. D. (2000). Educational policy on emotional intelligence: Does itmake sense? Educational Psychology Review, 12(2), 163-183. 4DIJMS. 